RESEARCH PAPER RP1494

Part of Journal of Research of the National Bureau of Standards, Volume 29, August 1942

\title{
X-RAY MEASUREMENT OF THE THICKNESS OF THE COLD-WORKED SURFACE LAYER RESULTING FROM METALLOGRAPHIC POLISHING
}

\author{
By Herbert C. Vacher
}

\begin{abstract}
Different thicknesses of cold-worked layers, each representative of a specific abrasive treatment used in metallographic polishing, were produced on annealed specimens of steel $(0.34 \% \mathrm{C})$, copper, and aluminum. The back-reflection patterns of the specimens showed a progressive increase in the degree of diffuseness with thickness in the range from 2 to 25 microns on the steel specimens, 2 to 42 microns on the copper specimens, and 5 to 95 microns on the aluminum specimens. A comparison of these patterns with others obtained from copper and steel specimens indicated that the cold-worked layers produced by certain fineabrasive treatments were thicker than those produced by certain coarse-abrasive treatments.
\end{abstract}

\section{CONTENTS}

I. Introduction

II. Preparation of representative abraded surfaces_............ 178

III. Thickness of the altered surface layer

IV. Back-reflection patterns of representative abraded surfaces _....... 179

V. Reduction of thickness of a cold-worked layer by specific abrasive treatments_...

VI. Summary _............. 181

\section{INTRODUCTION}

The purpose of metallographic polishing, consisting in a series of abrasive treatments, is to produce a smooth flat surface with minimum alteration of structure of the metal at the surface. The film of altered metal, invariably present at the surface, should be removable by a a light etch. Frequently, however, microscopic examination of the etched surface fails to reveal a structure truly characteristic of the metal, the structure being modified by the various abrasive treatments used. Obviously there is need for a method for estimating the extent to which the normal structure is affected by each abrasive treatment used. In this way an individual abrasive treatment could be evaluated with respect to its effect on the thickness of a structurally altered layer as well as the surface characteristics, such as fineness of scratches and pitting.

Consideration of X-ray patterns produced by the back-reflection method led to the conclusion that this method could be used to detect structural changes in the surface layer of a metal, such as low-carbon steel, copper, and aluminum, when in the annealed condition. A back-reflection pattern, obtained by conventional methods, records reflections from planes of crystals located as much as 0.001 to 0.002 inch (25 to 50 microns) below the surface. Alteration in the structure 


\section{Journal of Research of the National Bureau of Standards}

of an annealed metal in a layer of this thickness would result in a change in the appearance of the X-ray pattern. In the following experiments, back-reflection patterns were made, and the thickness of the cold-worked surface layer was determined for steel $(0.34 \% \mathrm{C})$, oxygen-free copper, and aluminum specimens that were representative of specific abrasive treatments commonly used in metallographic polishing.

\section{PREPARATION OF REPRESENTATIVE ABRADED SURFACES}

The steel specimens (1-inch squares $1 / 4$ inch thick) were cut from an annealed plate, the copper specimens (7/8-inch disks $1 / 4$ inch thick) from an annealed rod of oxygen-free copper, and the aluminum specimens (1-inch disks $1 / 4$ inch thick) from a rod of annealed commercially pure aluminum. Surfaces representative of different abrasive treatments were prepared on these specimens as follows: Smooth surfaces, free from cold-work, were prepared by conventional metallographic polishing and etching procedures. The completeness of the removal of the cold-worked layer was established for a number of specimens by the presence of well-defined spots in the back-reflection patterns of the etched surfaces. Each surface then was abraded by one of the treatments listed in table 1. This covered the surface completely with nearly parallel scratches, after which the specimen was turned 90 degrees and the abrasion continued until the first scratches were removed. The back-reflection patterns of the aluminum specimens obtained prior to abrasion indicated that they were not in the fully annealed condition. These specimens were annealed separately in a gas flame and then abraded.

TABLE 1.-Thickness of the altered surface layer on metals after different abrasive treatments

\begin{tabular}{|c|c|c|c|c|}
\hline \multirow{2}{*}{ Abrasive } & \multicolumn{3}{|c|}{ Thickness of altered layer } & \multirow{2}{*}{$\begin{array}{l}\text { Corres- } \\
\text { ponding } \\
\text { diffraction } \\
\text { patterns }\end{array}$} \\
\hline & Steel & Copper & Aluminum & \\
\hline (1) Levig & Microns & Microns $_{2}$ & Microns & \\
\hline (2) Aluminum oxide (Alundum) powder, grit No. $600^{1}$ & & & & 2 \\
\hline $\begin{array}{l}\text { (3) Emery polishing paper, grit No. } 3 / 0^{2} \\
\text { (4) Emery polishing paper, grit No. } 0^{2}\end{array}$ & 13 & 21 & 50 & \\
\hline $\begin{array}{l}\text { (4) Emery polishing paper, grit No. } 0^{2} \\
\text { (5) Aluminum oxide (Aloxite) polishing paper grit No. }\end{array}$ & & & & \\
\hline (6) Emery polishing paper, grit No. $1-\mathrm{G}^{2}$ & $\stackrel{5}{12,5}$ & 12 & 33 & \\
\hline (7) Aluminum oxide cloth-backed belt, grit No. $100^{4}$ & 25 & & 95 & \\
\hline
\end{tabular}

1 A specimen was pressed lightly by hand against a power-driven disk rotating in a vertical plane, covered with broadcloth which had been sprayed with a water suspension of the abrasive.

2 The abrasive paper was kept covered with a kerosine-paraffin solution, and the specimen was abraded by moving it manually back and forth under light pressure.

a A specimen was abraded in the same way as described in footnote 2 but without a lubricant.

- A specimen was abraded by holding it under light pressure against a power-driven horizontal belt.

\section{THICKNESS OF THE ALTERED SURFACE LAYER}

The method used in determining the thickness of the surface layer, throughout which the structure of the metal had been altered, to some extent at least, by the abrasive treatments was a repetition of the following sequence of operations: A back-reflection pattern was obtained from the surface, a small amount of metal was removed by treatment with a suitable solvent, and the loss in weight was determined. Radiation from a chromium target was used in obtaining the back-reflection patterns. At the stage when no further change in 
the definition of the spots in the X-ray patterns could be detected, the thickness of the layer removed by the successive treatments with the solvent was computed from the loss in weight, initial area, and density of the specimen. In order to facilitate the detection of small changes in the definition of the spots, special care was taken after each treatment to replace the specimen in the same position with respect to the collimated beam.

The treatment used to remove a small amount of metal from the iron and copper specimens consisted in an electrolytic (anodic) etch. The electrolyte was a 0.5 -percent solution of hydrochloric acid for iron and a 2-percent solution of ammonium persulfate for copper. Flick's etch ${ }^{1}$ was used for the aluminum specimens.

The values obtained for the thickness of the structurally altered layer representative of different abrasive treatments are listed in table 1. It is noteworthy that with the exception of the No. 100-grit belt, abrasion with No. 3/0 emery polishing paper affected the metal to a greater depth than the coarser-abrasive treatments. This has been taken to indicate that the rolling action of loose abrasive particles, torn from the paper during an abrasive treatment, is a serious factor when minimum alteration of the structure is desired. It may also indicate that even when care is taken fine scratches do not necessarily signify a thinner altered surface layer than do coarse scratches. The results (table 1) also show that for the same abrasive treatment the thickness of such a layer increases on steel, copper, and aluminum in the order given. This is in agreement with the relative difficulty encountered in preparing a satisfactory surface on these metals for metallographic examination.

\section{BACK-REFLECTION PATTERNS OF REPRESENTATIVE ABRADED SURFACES}

The back-reflection X-ray patterns of the representative abraded surfaces were obtained with a cold-cathode tube ${ }^{2}$ operating on a halfwave rectified current of 5 to $7 \mathrm{ma}$ at about $30 \mathrm{kvp}$. The exposures were 1 to $1 \frac{1}{2}$ hours, and a collimator consisting of two 1-mm drill holes $6 \mathrm{~cm}$ apart was used. Prints showing 60-degree sections of the circular patterns, arranged in order of increasing thickness of the structurally altered layer of the three materials used, are shown in figures 1,2 , and 3 , respectively. The $A$ sections show patterns obtained by using a cobalt target for the steel specimens and a copper target for the copper and aluminum specimens; the $B$ sections show patterns obtained by using a chromium target.

An inspection ${ }^{3}$ of the patterns in figures 1,2,3 and of the results in table 1 shows that in nearly every case there was a detectable increase in the degree of diffuseness for each increase in the thickness of the layer affected by the abrasive treatment and that, in general, small changes can be detected more easily in patterns obtained by using a chromium target than by using a cobalt or copper target. The degree of diffuseness of back-reflection patterns obtained by a conventional procedure, therefore, can be used to estimate relative differences in the thicknesses of cold-worked layers.

\footnotetext{
1 Flick's etch consists in immersing the specimen in a solution containing $10 \mathrm{ml}$ of $\mathrm{HF}, 15 \mathrm{ml}$ of $\mathrm{HCl}$, and $90 \mathrm{ml}$ of $\mathrm{H}_{2} \mathrm{O}$, then washing in warm water, following with a dip in concentrated $\mathrm{HNO}_{3}$.

2 C. J. Ksanda, A metal X-ray tube for characteristic radiation, Rev. Sci. Instr. 3, 531-534 (1932); American Instrument Co., Silver Spring, Md. Bul. 1045 (1938).

3 The comparisons described in the following discussion were made from an inspection of the pattern on the original negative. It is not always possible to detect small differences in the diffuseness of patterns by com. paring the prints.
} 
Inspection of the $6 A$ and $6 B$ sections (figs. 1, 2, and 3) shows that a few diffuse spots were obtained from surfaces abraded with No. 100grit abrasive when cobalt and copper targets were used and a diffuse ring when a chromium target was used. This indicated that the maximum thickness of cold-worked layers that can be estimated by increases in the degree of diffuseness are about 25 microns on annealed steel, 42 on annealed copper, and 95 on annealed aluminum. The minimum thickness of cold-worked layers that could be detected on these metals was determined in the following way. Back-reflection patterns made of representative surfaces finished with rouge and magnesia, respectively, showed no detectable change in diffuseness when compared with patterns obtained from the same surfaces prior to the finishing treatments. A comparison of the $1 A$ and $1 B$ sections with the $2 A$ and $2 B$ sections (figs. 1, 2, and 3 ) shows that abrasion with levigated alumina on the steel and copper specimens and with grit No. 600 aluminum odide powder on the aluminum specimens caused a barely detectable blurring of the spots. This was more noticeable in patterns obtained with a chromium target than with a cobalt or copper target. Hence (table 1) the minimum thickness of a structurally altered layer that can be detected is about 2 microns on annealed steel and annealed copper and 5 microns on annealed aluminum.

In some metallographic polishing procedures the use of No. 3/0 emery polishing paper is followed by treatment on a wet canvas lap loaded with grit No. 320 aluminum oxide powder (Alundum). Sometimes several of the successive treatments on abrasive papers are replaced by treatments on lead-tin laps loaded respectively with a coarse and a fine emery. To estimate the thickness of the layer affected by various treatments of this kind on annealed copper, backreflection patterns were made of surfaces representative of each. A comparison of the patterns with those in figure $2, B$, indicated that the layer showing structural changes resulting from treatments on lead-tin laps loaded with grade Nos. 302 and 3031/2 emery (American Optical Co.) was thicker than that resulting from No. 3/0 emery polishing paper, and in the case of treatment on the canvas lap, loaded with No. 320 aluminum oxide powder, was less than that resulting from No. 400-grit paper. It was concluded that, in polishing annealed copper specimens for metallographic examination, treatment on a canvas lap should follow, whenever possible, a treatment on No. 400grit paper, and treatments on No. $3 / 0$ emery polishing paper and leadtin laps should be omitted.

\section{REDUCTION OF THICKNESS OF A COLD-WORKED LAYER BY SPECIFIC ABRASIVE TREATMENTS}

A few experiments were made with annealed-copper specimens to determine if the thickness of the altered surface layer representative of a coarse abrasive could be reduced to that representative of a fine-abrasive treatment by a single treatment. For the remainder of this discussion an abrasive treatment is defined as abrasion in a direction 90 degrees to the direction of a previous abrasion sufficient to remove the scratches caused by the latter. Back-reflection patterns were obtained after each of the following abrasive treatments: (1) No. 100-grit belt; (2) No. 1-G grit emery paper; (3) treatment (2) repeated; (4) No. 400-grit paper; (5) treatment (4) repeated; (6) No. 320 aluminum oxide powder on a canvas lap. Sections of the circular patterns corresponding to these treatments are shown in figure $4, B$. 


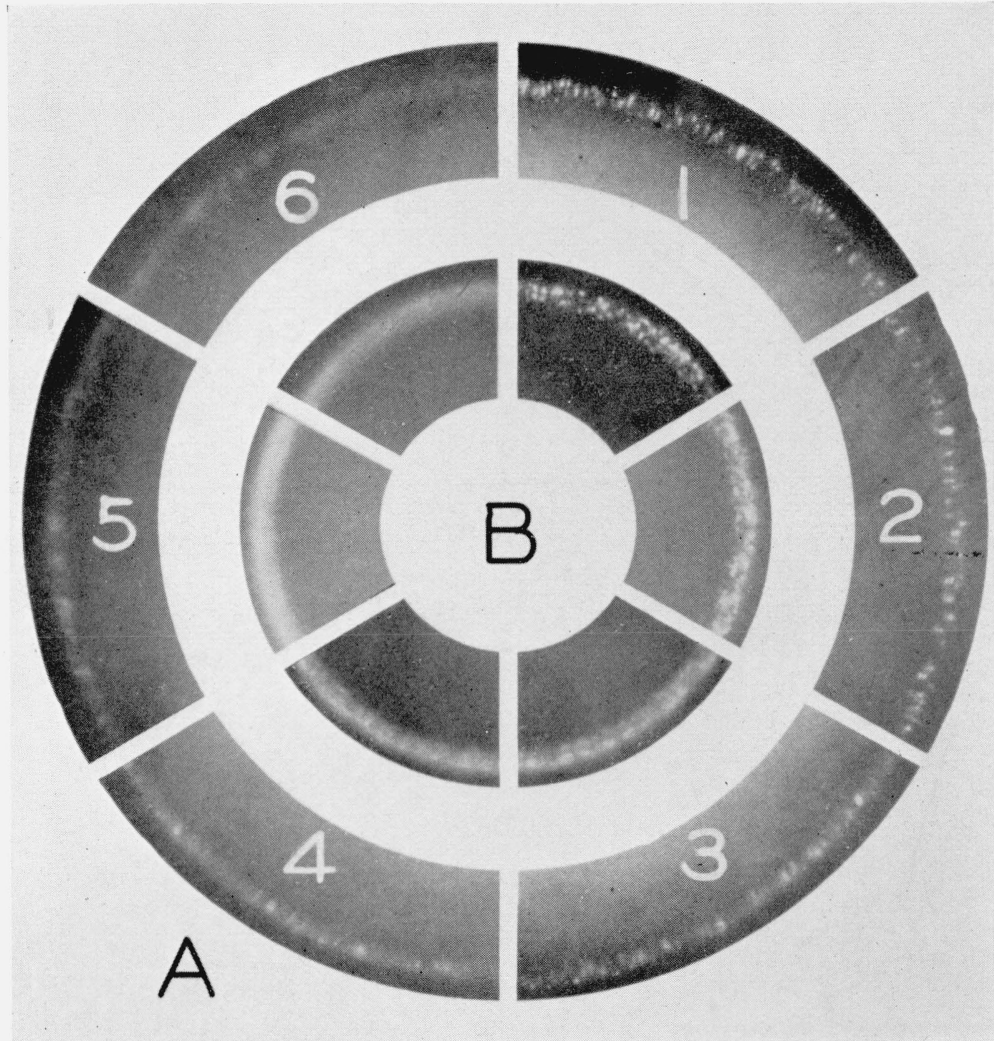

FIGURE 1.-Back-reflection X-ray patterns of surfaces on annealed steel (0.34 C).

Patterns 1 indicate the condition of the surface layer prior to specific abrasive treatments; patterns 2 indicate the alteration of this condition by levigated alumina; patterns 3 by No. 400-grit paper; patterns 4 by No. 1-G grit emery paper; patterns 5 by No. $3 / 0$ emery polishing paper; patterns 6 by No. 100-grit belt. The $A$ and $B$ patterns were obtained by using cobalt and chromium targets, respectively. The film-to-specimen distances were 3.2 and $5.5 \mathrm{~cm}$, respectively. 


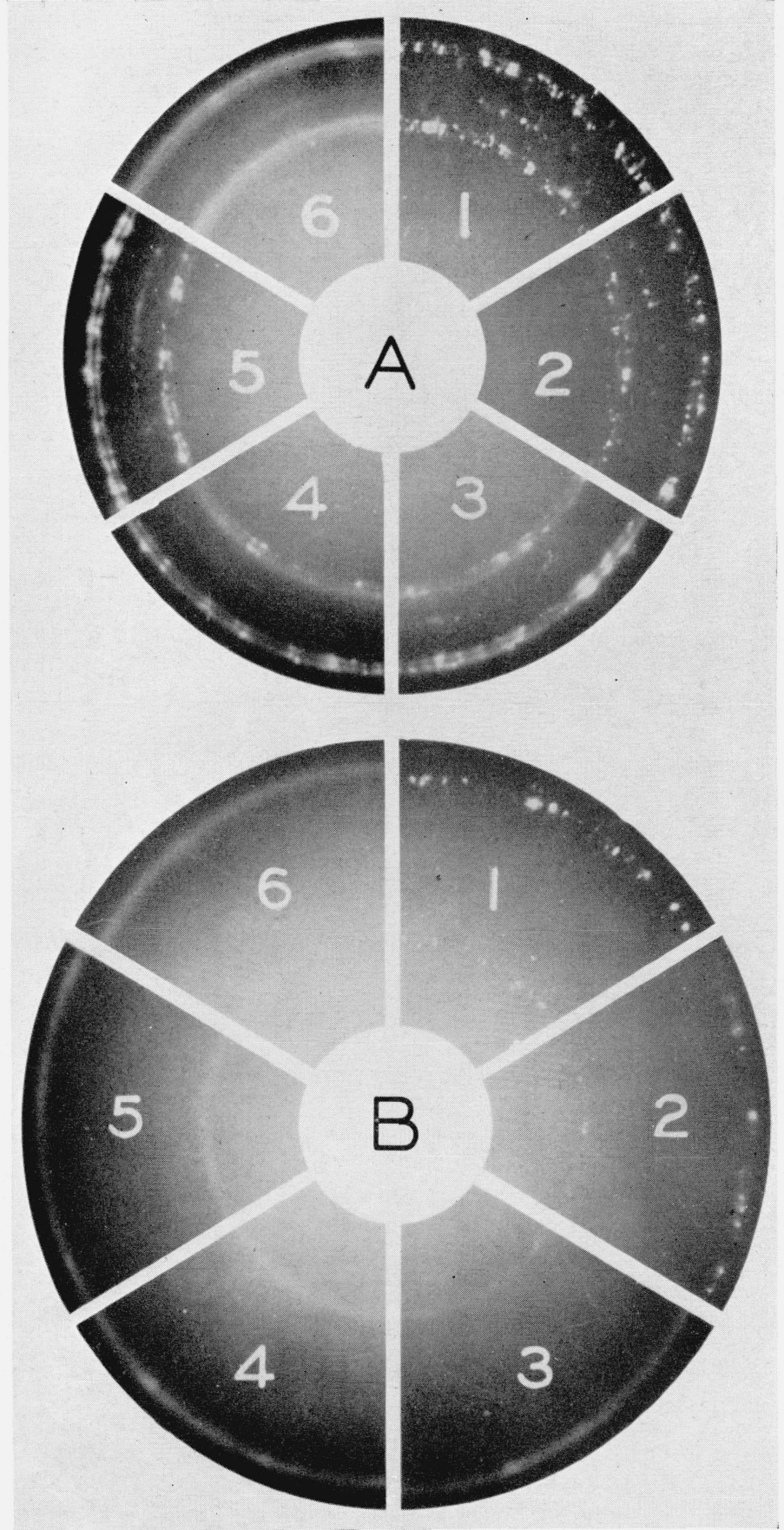

FiguRE 2.-Back-reflection X-ray patterns of surfaces on annealed copper.

Patterns 1 indicate the condition of the surface laver prior to specific abrasive treatments. Patterns 2 indicate the alteration of this condition by levigated alumina; patterns 3 by No. 400 -grit paper; patterns 4 by No. 1-G grit emery paper; patterns 5 by No. $3 / 0$ emery polishing paper; patterns 6 by No. 100 -grit belt. The $A$ and $B$ patterns were obtained by using copper and chromium targets, respectively. The film-tospecimen distances were 4.35 and $3.65 \mathrm{~cm}$, respectively. 


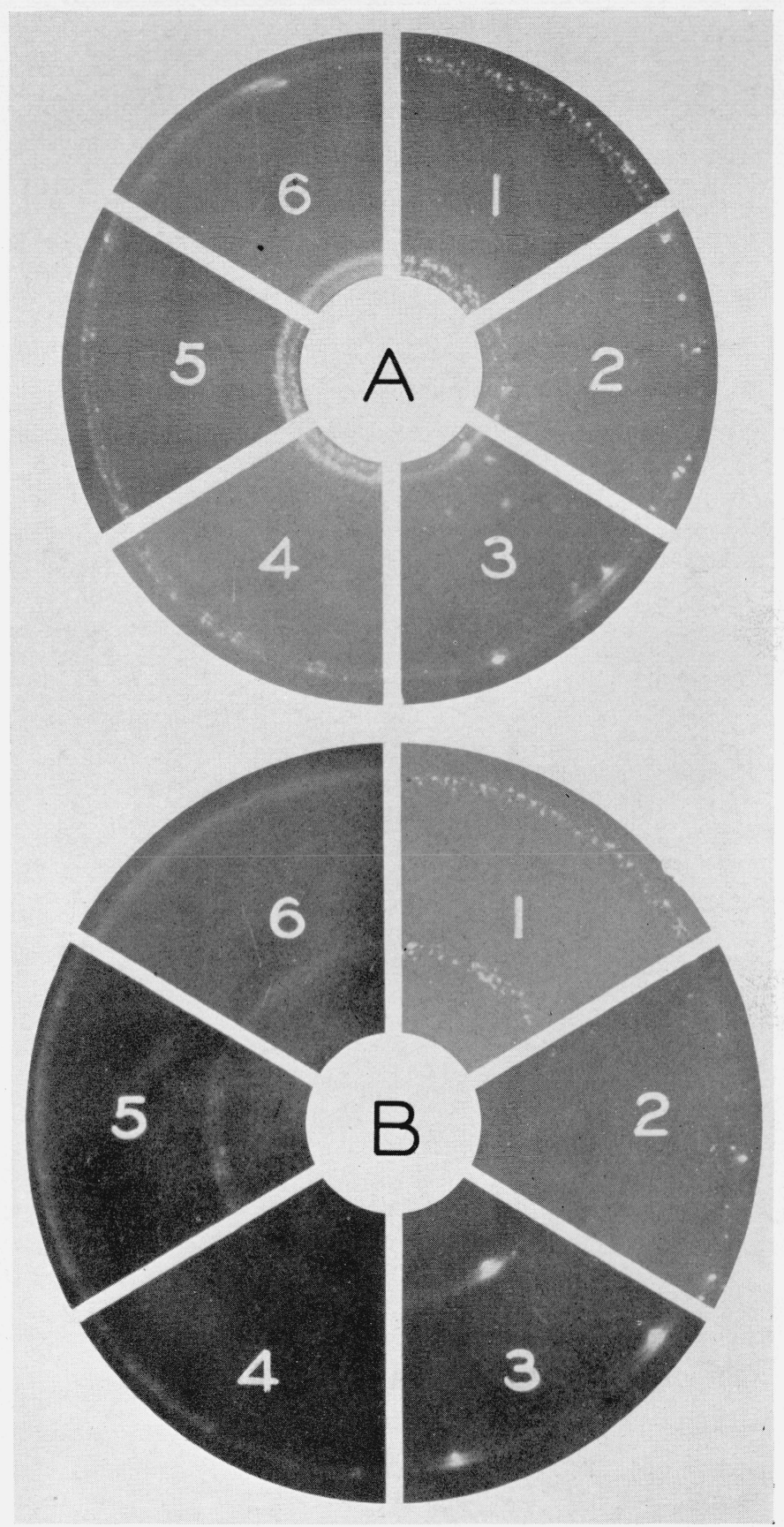

FiguRE 3.-Back-reflection X-ray patterns of surfaces on annealed aluminum.

Patterns 1 indicate the condition of the surface layer prior to specific abrasive treatments; patterns 2 indicate the alteration of this condition by No. 600 aluminum oxide powder, patterns 3 by No. 0 emery polishing paper; patterns 4 by No. 1-G grit emery paper; patterns 5 by No. $3 / 0$ emery polishing paper; patterns 6 by No. 100-grit belt. The $A$ and $B$ patterns were obtained by using copper and chromium targets, respectively. The film-to-specimen distances were 4.45 and $5.5 \mathrm{~cm}$, respectively. 


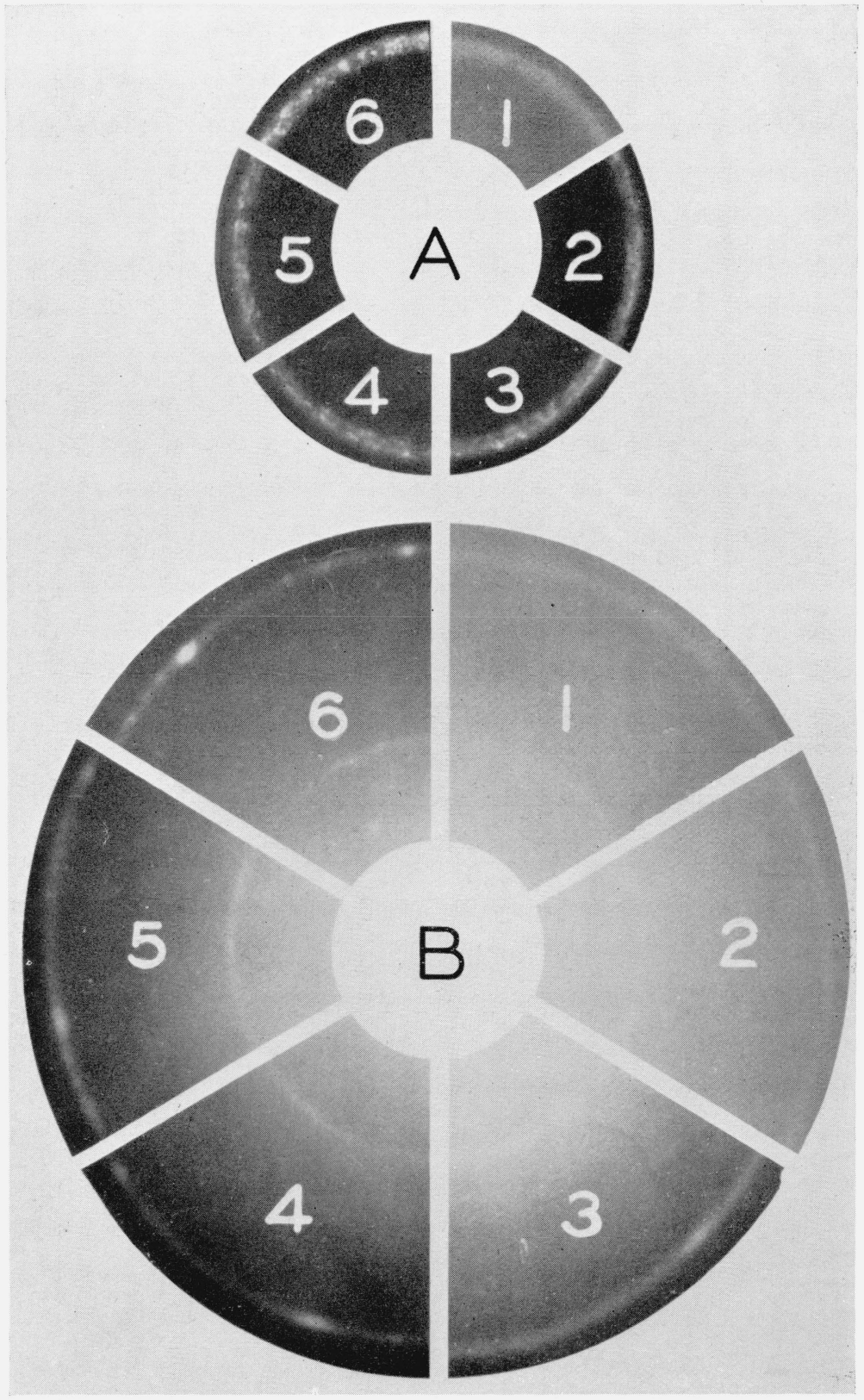

FIGURE 4.-Back-reflection patterns of surfaces after successive abrasive treatments.

$A$ patterns-steel specimen: pattern 1 by No. 100-grit belt; pattern 2 by No. 1-G grit paper; pattern 3 by No. 400-grit paper; patterns 4 and 5 by fine and coarse lead-tin laps, respectively; pattern 6 by rouge on a wet velvet lap.

$B$ patterns - copper specimen: pattern 1 by No. 100-grit belt; patterns 2 and 3 by No. 1-G grit paper first and second treatments, respectively; patterns 4 and 5 by No. 400 -grit paper first and second treatments, respectively; pattern 6 by No. 320 aluminum oxide powder on a wet canvas lap. 
A comparison of patterns 2 and 3 with pattern $5 B$ of figure 2 shows that two abrasive treatments with No. 1-G grit emery paper were necessary to reduce the thickness of the altered surface layer resulting from abrasion on a No. 100-grit belt to that representative of No. 1-G grit emery paper. A comparison of patterns 4 and 5 with pattern $3 B$ of figure 2 shows that this also was true for No. 1-G grit paper when followed by No. 400-grit paper. Pattern 6 shows that the thickness of the cold-worked surface layer after treatment (5) was reduced further by one treatment with No. 320 aluminum oxide powder on a canvas lap but not sufficient to be representative of the latter. In general, these results indicate that the cold-worked layer produced by a series of abrasive treatments with abrasives of increasing fineness is thicker than the cold-worked layer produced by many treatments of the last member of the series when used alone.

The reduction in the thickness of the altered surface layer on a steel specimen by a series of abrasive treatments, frequently employed to attain a metallographic polish, was determined by means of backreflection patterns. The abrasive treatments were (1) No. 100-grit belt; (2) No. 1-G grit emery paper; (3) No. 400-grit aluminum oxide paper; (4) lead-tin lap loaded with grade No. 302 emery; (5) leadtin lap loaded with grade No. 3031/2 emery; (6) $1 / 2$ hour on a rotating velvet lap loaded with rouge. A comparison of the back-reflection patterns obtained (fig. 4, A) indicates that the altered surface layer was increasingly thinner for the No. 1-G grit (pattern 2) and No. 400grit papers (pattern 3). However, for the coarse lead-tin (pattern 4) little or no difference was noted, and for the fine lead-tin (pattern 5) and rouge (pattern 6) laps, only slight improvement was obtained. A comparison of pattern 6 with pattern $3 B$ of figure 1 indicates that the thickness of the altered surface layer was about equal to that representative of No. 400-grit paper. If the thickness had been reduced to the value representative of rouge, pattern 6 of figure 4 should appear as pattern $1 B$ of figure 1 . These results indicate that the thickness of the altered layer would have been less if additional abrasive treatments with the No. 1-G grit and No. 400-grit papers had been made and the lap treatment had been omitted.

\section{SUMMARY}

A series of annealed specimens, each having a surface free from cold-work, was prepared from each of the following metals: steel $(0.34 \% \mathrm{C})$, copper, and aluminum. The surface was finished with one of several abrasives commonly used in preparing a surface for metallographic examination, and X-ray back-reflection patterns were obtained by using copper, cobalt, and chromium targets. The thicknesses of the layers altered by the abrasive treatments then were determined. The results showed that back-reflection patterns can be used to estimate the thicknesses of cold-worked layers between 2 and 25 microns on annealed steel, 2 and 42 microns on annealed copper, and 5 and 95 microns on annealed aluminum.

The experiments are described to illustrate the use of back-reflection $\mathrm{X}$-ray patterns as a means of evaluating individual abrasive treatments employed in obtaining a metallographic polish.

WASHINGTON, June 12, 1942. 


\section{NATIONAL BUREAU OF STANDARDS,}

WASHINGTON, D. C.

Send me the Mathematical Tables marked X below. I enclose remittance ${ }^{\mathbf{1}}$ to cover the cost.

\begin{tabular}{|c|c|c|c|c|}
\hline \multirow[b]{2}{*}{ Mark X } & \multirow[b]{2}{*}{ Title of publication } & \multicolumn{2}{|c|}{ Price } & \multirow[b]{2}{*}{ Amount enclosed } \\
\hline & & $\begin{array}{l}\text { United States and } \\
\text { its possessions, } \\
\text { and countries ex- } \\
\text { tending franking } \\
\text { privilege }\end{array}$ & Other countries & \\
\hline 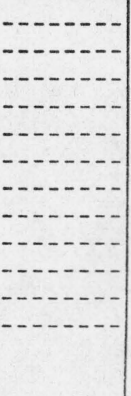 & $\begin{array}{l}\text { MT1. Table of the first ten powers of the integers from } 1 \text { to } \\
\text { MT2. Tables of the exponential function } e^{x} \\
\text { MT3. Tables of circular and hyperbolic sines and cosines for radian arguments } \\
\text { MT4. Tables of sines and cosines for radian arguments } \\
\text { MT5. Tables of sine, cosine, and exponential integrals, volume I } \\
\text { MT6. Tables of sine, cosine, and exponential integrals, volume II } \\
\text { MT7. Table of natural logarithms, volume I } \\
\text { MT8. Tables of probability functions, volume I } \\
\text { MT9. Table of natural logarithms, volume II } \\
\text { MT10. Table of natural logarithms, volume III } \\
\text { MT11. Tables of moments of inertia and section moduli } \\
\text { MT12. Table of natural logarithms, volume IV }\end{array}$ & $\begin{array}{r}\$ 0.50 \\
2.00 \\
\text { 2. } 00 \\
\text { 2. } 00 \\
\text { 2. } 00 \\
\text { 2. } 00 \\
\text { 2. } 00 \\
\text { 2. } 00 \\
\text { 2. } 00 \\
\text { 2. } 00 \\
\text { 1. } 25 \\
\text { 2. } 00\end{array}$ & $\begin{array}{l}\$ 0.65 \\
2.50 \\
2.50 \\
2.50 \\
2.50 \\
2.50 \\
2.50 \\
2.50 \\
2.50 \\
2.50 \\
\text { 1. } 50 \\
2.50\end{array}$ & 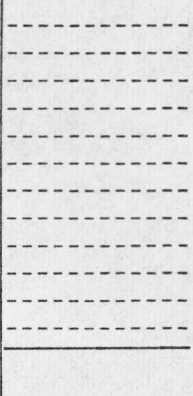 \\
\hline
\end{tabular}

1 Remittance should be in form of post-office money order, or check, and made payable to the order of the "National Bureau of Standards" in United States currency.

Send to

Number and Street.

City and State 


\section{MATHEMATICAL TABLES}

Attention is invited to a series of publications which is being prepared by the Project for the Computation of Mathematical Tables conducted by the Federal Works Agency, Work Projects Administration for the City of New York under the sponsorship of the National Bureau of Standards.

To date, ten tables have been made available through the National Bureau of Standards. These are listed below:

MT1. Table or the First Ten Powers of the Integers From 1 to 1000:

(1938) VIII+ 80 pages; heavy paper cover. 50 cents.

MT2. Tables of the Exponential Function $e^{x}$ :

The ranges and intervals of the argument and the number of decimal places in the entries are given below:

$\begin{array}{rcc}\text { Range of } x & \text { Interval of } x & \text { Decimals given } \\ -2.5000 \text { to } 1.0000 & 0.0001 & 18 \\ 1.0000 \text { to } 2.5000 & .0001 & 15 \\ 2.500 \text { to } 5.000 & .001 & 15 \\ 5.00 \text { to } 10.00 & .01 & 12\end{array}$

(1939) XV+535 pages; bound in buckram, $\$ 2.00$.

MT3. Tables of Circular and Hyperbolic Sings and Cosings por Radian Argument8:

Contains 9 decimal place values of $\sin x, \cos x, \sinh x$ and $\cosh x$ for $x$ (in radians) ranging from 0 to 2 at intervals of 0.0001 .

(1939) XVII + 405 pages; bound in buckram, $\$ 2.00$.

MT4. Tables or Sinks and Cosineg for Radian Arguments:

Contains 8 decimal place values of sines and cosines for radian arguments ranging from 0 to 25 at intervals of 0.001 .

(1940) XXIX+275 pages; bound in buckram, $\$ 2.00$.

MT5. Tables or Sinr, Cosine, and Exponential Integrals, Volume I:

Values of these functions to 9 places of decimals from 0 to 2 at intervals of 0.0001 .

(1940) XXVI+444 pages; bound in buckram, $\$ 2.00$.

MT6. Tables of Sine, Cosine, and Exponential Intrgrals, Volume II:

Values of these functions to 9,10 , or 11 significant figures from 0 to 10 at intervals of 0.001 , with auxiliary tables.

(1940) XXXVII + 225 pages; bound in buckram, $\$ 2.00$.

\section{MT7. Table or Natural Logarithms, Volume I:}

Logarithms of the integers from 1 to 50,000 to 16 places of decimals.

(1941) XVIII + 501 pages; bound in buckram, $\$ 2.00$.

MT8. Tables of Probability Functions, Volumb I:

Values of these functions to 15 places of decimals from 0 to 1 at intervals of 0.0001 and 1 to 5.6 at intervals of 0.001 .

(1941) XXVIII + 302 pages; bound in buckram, $\$ 2.00$.

MT9. Table of Natural Logarithms, Volume II:

Logarithms of the integers from 50,000 to 100,000 to 16 places of decimals.

(1941) XVIII + 501 pages; bound in buckram; $\$ 2.00$.

[Continued on p. 4 of cover] 
(continued from p. 3 of cover)

MT10. Table of Natural Logarthms, Volume III

Logarithms of the decimal numbers from 0.0001 to 5.0000 , to 16 places of decimals. (1941) XVIII + 501 pages; bound in buckram, $\$ 2.00$.

MT11. Tables of the Mombnts of Ingrtia and Section Moduli of Ordinary Angles, Channgls, and Bulb Anglgs with Certain Platb Combinations.

(1941) XIII + 197 pages; bound in green cloth. \$1.25.

MT12. Table or Natural Logarithms, Volumb IV:

Logarithms of the decimal numbers from 5.0000 to 10.0000 , to 16 places of decimals.

(1941) XXII + 506 pages; bound in buckram, $\$ 2.00$.

Payment is required in advance. Make remittance payable to the "National Bureau of Standards", and send with order, using the blank form facing page 3 of the cover.

The prices are for delivery in the United States and its possessions and in countries extending the franking privilege. To other countries the price of MT1 is 65 cents; that of MT2, MT3, MT4, MT5, MT6, MT7, MT8, MT9, MT10, and MT12 is $\$ 2.50$ each; and that of MT11 is $\$ 1.50$; remittance to be made payable in United States currency.

Copies of these publications have been sent to various Government depositories throughout the country, such as public libraries in large cities, and colleges and universities, where they may be consulted.

A mailing list is maintained for those who desire to receive announcements regarding new tables as they become available. A list of the tables it is planned to publish will be sent on request. 